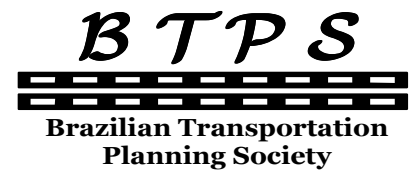

Journal of Transport Literature

Vol. 7, n. 2, pp. 319-337, Apr. 2013

Research Directory
JTL | RELIT

www.transport-literature.org

\title{
A model for estimating airline passenger trip reliability metrics from system-wide flight simulations
}

\author{
[Um modelo para estimar métricas de confiabilidade de viagens de passageiros das companhias aéreas \\ a partir de simulações de voo sistêmicas] \\ Lance Sherry* \\ George Mason University, USA
}

Submitted 19 Jul 2012; received in revised form 6 Aug 2012; accepted 9 Aug 2012

\begin{abstract}
Analysis of the benefits of government modernization initiatives for airports or air traffic control are conducted using complex software models that simulate up to 60,000 flights per day. These flight-centric simulations do not model passenger flows and therefore do not account for passenger trip delays due to cancelled flights and missed connections, which account for up to $60 \%$ of the total passenger trip delays. This paper describes a closed-form model for estimating passenger trip reliability metrics from flight delay data from system-wide simulations. The outputs of the model, (i) percent passengers disrupted, (ii) average passenger trip delay, and (iii) total passenger trip delays, are derived from the probability of delayed flights and network structure parameters. The model highlights the role of network structure, in addition to flight on-time performance, on passenger trip reliability. These results have implications for government and industry initiatives to improve flight on-time performance through modernization, consumer protection, and the conduct of benefits analysis.
\end{abstract}

Key words: passenger trip delays, airline operations, nas-wide simulations, reliability metrics.

\section{Resumo}

Neste trabalho, foram conduzidas análises dos benefícios de iniciativas governamentais de modernização de aeroportos ou controle de tráfego aéreo utilizando programas complexos de modelos que simulam até 60.000 voos por dia. Estas simulações de vôo não modelam fluxos de passageiros e, portanto, não levam em consideração os atrasos de viagens devido a cancelamento de voos e conexões perdidas, que respondem por até $60 \%$ do total dos atrasos de viagem de passageiros. Este trabalho descreve um modelo de forma fechada para estimar métricas confiabilidade de viagem de passageiros a partir de dados de atraso de vôo obtidas de simulações do sistema aéreo. As variáveis de resultado do modelo, (i) percentual de passageiros afetados, (ii) o atraso médio de viagem do passageiro e (iii) o total de atrasos computados, são derivados a partir da probabilidade de voos atrasados e de parâmetros de estrutura de rede. 0 modelo enfatiza o papel da estrutura de rede, além do desempenho dos tempos, na confiabilidade da viagem do passageiro. Estes resultados têm implicações para as iniciativas do governo e da indústria em melhorar o desempenho de tempos de vôo por meio da modernização, da defesa do consumidor, e da realização de análise de benefícios.

Palavras-Chave: atrasos de viagem, operações de companhias aéreas, simulação do sistema aéreo, métricas de confiabilidade.

*Email: lsherry@gmu.edu.

\section{Recommended Citation}

Sherry, L. (2013) A model for estimating airline passenger trip reliability metrics from system-wide flight simulations. Journal of Transport Literature, vol. 7, n. 2, pp. 319-337.

- JTL/RELIT is a fully electronic, peer-reviewed, open access, international journal focused on emerging transport markets and published by BPTS - Brazilian Transport Planning Society. Website www.transport-literature.org. ISSN 2238-1031. 


\section{Introduction}

The airlines provide a critical service to the U.S. economy, providing rapid, safe, and affordable inter-city transportation. The reliability of this transportation service, defined as the difference between the ticketed arrival time at the destination and the actual passenger arrival time at the destination, is measured by three metrics: (1) Total Passenger Trip Delays; (2) Percentage of Passengers Disrupted; (3) Average Trip Delay for a Disrupted Passenger.

In 2007, the Annual Total Passenger Trip Delays for U.S. domestic passengers were estimated at 28,539 years with one out of four passengers experiencing a disrupted trip with an average trip disruption of 110 minutes (Sherry, 2010; Barnhart et, al. 2010). These trips delays were estimated to the cost the U.S. economy $\$ 16.1 \mathrm{~B}$ in lost economic productivity (NEXTOR, 2010).

The U.S. government and industry are actively collaborating on approaches to increase the capacity and the productivity of the infrastructure required to operate the airline transportation system (ATS). The Airport Improvement Plan (FAA, 2010) is designed to relieve the bottlenecks at U.S. airports by adding runways, taxiways, gates, terminal buildings and service facilities at key nodes of the air-transportation system. NextGen (JPDO, 2010) is an Air Traffic Control modernization program to improve the productivity and utilization of existing airspace and resources.

The benefits of these modernization initiatives are derived from simulations of the National Airspace System (NAS) that fly up to 60,000 flights per day with alternate proposed conceptsof-operations and technologies. These NAS-wide Simulations, such as SWAC (Post, 2011), NASPAC (Millner, 1993), LMINet (Long et al., 1999), FACET (Bilmoria, et, al., 2000), ACES (Sweet et. al.2002), and PNP (Ramamoorthy et al.,2006), provide decision-makers estimates of the benefits derived from the modernization initiatives in the form of flights delays, distance travelled, and airspace utilization. These parameters translate into reduced costs of operation to airlines, reduced ANSP workload and staffing, increased safety margins, and reductions in emissions and noise. 
The results of the NAS simulations are also translated into estimates of national economic benefits in form of lost economic productivity. Lost productivity is derived by multiplying passenger trip delays to an estimate of the passenger value of time (DOT, 2003; Baik et al, 2010). Research using estimated passenger itineraries (Bratu \& Barnhart, 2005; Wang 2007; Zhu, 2007; Barnhart et al., 2010; Sherry et.al., 2010) have shown that accounting schemes that use only flight delays (not cancelled flights and missed connections) under-estimate the magnitude of passenger trip delays by as much as $60 \%$.

Further, an analysis of probabilistic models of canonical airline networks (Sherry, 2011) identified changes in airline network structure, such as the ratio between direct and connecting itineraries, the time between banks at the hubs, the frequency of service, and the selection of aircraft size and target load factors, play a significant role in passenger trip reliability performance. For example, for a 51 airport hub-and-spoke network, an increase in load factors between 7-10\% can nullify the benefits in total passenger trip delay achieved through a $5 \%$ increase in flight on-time performance.

To provide a full accounting of the impact of the benefits of modernization initiatives using NAS simulations, the flight performance data must be converted to passenger trip delay data. This conversion should take into account cancelled flights and missed connections, as well as the effects of the structure of the network.

Ball et. al. (2006) and Subramanian (2007) developed an aggregate model to estimate average passenger trip delays for delayed and cancelled flights. This model uses fixed estimates for the magnitude of delays and is ambivalent to the effects of network structure.

This paper describes the derivation of a set of equations for estimating all three metrics for passenger trip reliability from flight on-time performance generated by NAS-wide simulations (see Figure 1). The model includes passenger trip delays for delayed flights, cancelled flights, and missed connections. The model estimates the probability of disruptions as well as the magnitude of the delays. The model explicitly includes inputs to reflect the structure of the network. 


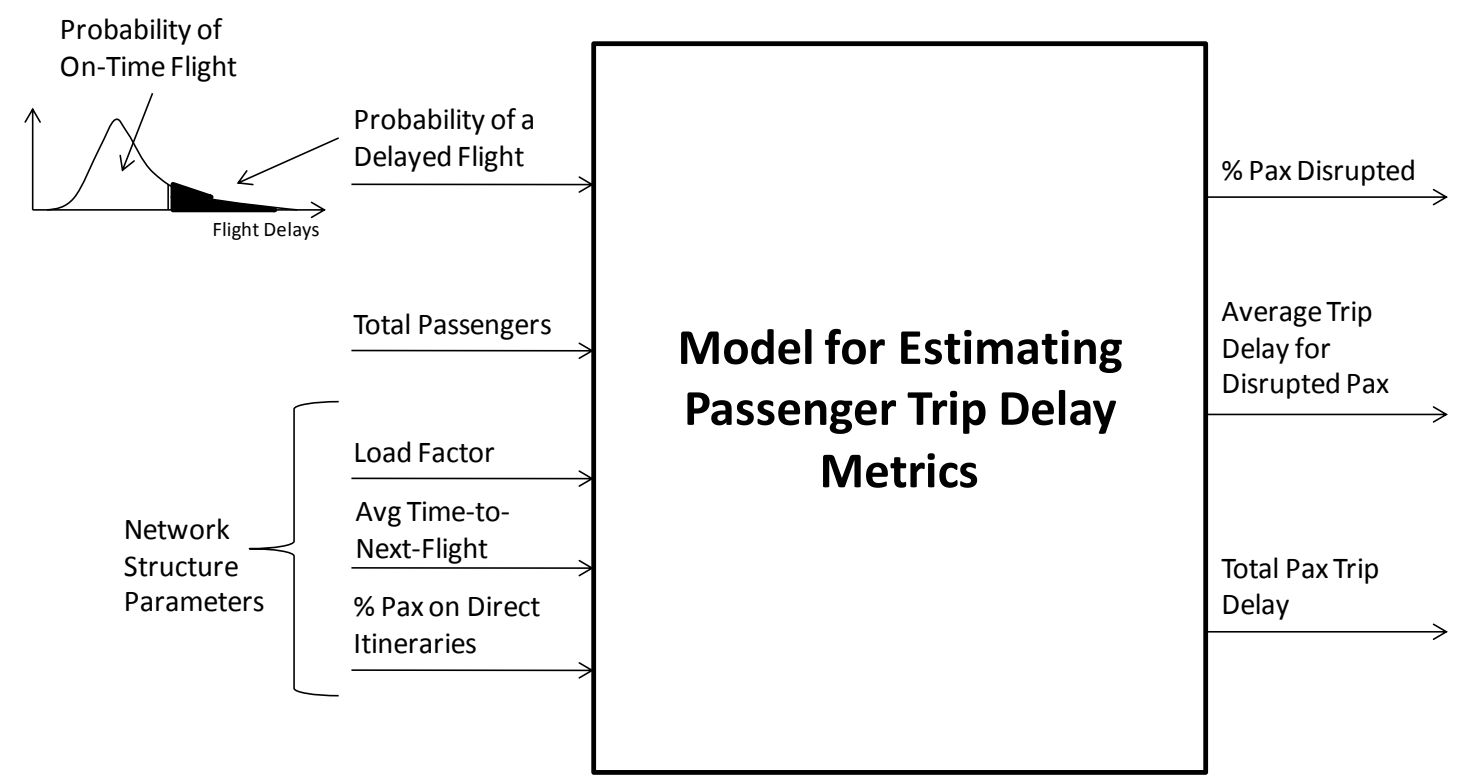

Figure 1 - Model for converting flight delays data to estimates of passenger trip reliability metrics

This paper is organized as follows: Section 1 describes the underlying constructs of passenger trip delays: flights, itineraries and disruptions. Section 2 describes passenger trip reliability metrics. Section 3 provides a definition or the terms, identities and relationships between terms. Section 4 provides a derivation of the equations. Section 5 provides a discussion of the implications of these results.

\section{Flights, itineraries and disruptions}

Airlines schedule and sell tickets to passengers for a transportation service between Origin and Destination (O/D) pairs. To maximize utilization of assets (e.g. aircraft, crews, gate agents, etc.), airlines operate a time-space network of flights that is synchronized with the ticketed schedule and the availability of capital equipment (e.g. aircraft, gates), material (e.g. fuel) and labor.

The building block of airline transportation is a flight between an origin and destination airport. A flight is defined by a unique date, flight number, an origin/destination, a scheduled departure time, a scheduled arrival time, an actual departure time, and an actual arrival a time. 
A flight is also defined uniquely by the available seats, load factor, and by its performance status: on-time, delayed, cancelled, diverted.

Feasible sequences of flights to ferry passengers from an origin to a destination are known as passenger itineraries. A passenger itinerary is defined uniquely by a single flight (e.g. AAL 123 ) or by a sequence of flights (e.g. UAL 345 and UAL 456), along with the number of passengers on the itinerary.

A passenger itinerary supported by a single flight is classified as a direct itinerary. A passenger itinerary supported by more than one flight is classified as a connecting itinerary. Each passenger itinerary is also uniquely classified by an itinerary status: on-time, delayed, rebooked due to missed connection, rebooked due to cancellation, and diverted.

\subsection{Networks and Itineraries}

Airlines schedule flights to operate in a time-space network of flights such that aircraft and crews can be positioned to operate the flights in contiguous manner throughout the day. A well designed network of itineraries will maximize revenue by meeting passengers travel demands with appropriate seat capacity, and minimize costs by using the most cost-effective aircraft, keeping the aircraft utilized as much as possible, and minimizing the impact of disruptions.

By definition, each flight in the network will have passengers with direct and connecting itineraries on board. For example, a Delta airlines flight from Washington, D.C. (DCA) to Atlanta (ATL), will have passengers flying on a direct itinerary from DCA to ATL, as well as passengers flying on connecting itineraries from DCA to ATL then on to DEN, MEM, LAX, etc. The number of passengers on each flight is the sum of all the passengers on each of the passenger itineraries that form that flight.

\subsection{Relationship between Flights and Itineraries}

Individual flights can be disrupted by delays or cancellations. The status of individual flights can be categorized as: on-time, delayed (by more than 15 minutes), or cancelled. Passenger itineraries can be disrupted by delayed flights, cancelled flights, or missed connections. The status of direct passenger itineraries can be categorized as: on-time, delayed (by more than 15 
minutes), or cancelled. The status of connecting passenger itineraries can be categorized as: on-time, delayed (by more than 15 minutes), cancelled, or missed connection.

The likelihood and magnitude of a disruption of each type of itinerary is summarized in Table I. For passengers on direct itineraries, the likelihood of a disruption in the form of a delayed itinerary is a function of the likelihood of a delayed flight. The magnitude of the delay for this itinerary is also determined by the magnitude of the delay of the flight.

Table 1 - Relationship between flights and itinerary disruptions. The likelihood and magnitude of each type of disruption

\begin{tabular}{|c|c|c|c|}
\hline Itinerary Type & $\begin{array}{c}\text { Causes of Itinerary } \\
\text { Disruption }\end{array}$ & $\begin{array}{c}\text { Probability of Itinerary } \\
\text { Disruption }\end{array}$ & $\begin{array}{c}\text { Magnitude of Itinerary } \\
\text { Disruption }\end{array}$ \\
\hline \multirow{2}{*}{ Direct } & Delayed flight & Probability of delayed flight & Magnitude of flight delays \\
\hline & Cancelled flight & Probability of cancelled flight & $\begin{array}{l}\text { Rebooking based on load factor } \\
\text { and frequency of service }\end{array}$ \\
\hline \multirow{3}{*}{ Connecting } & Delayed flight & $\begin{array}{l}\text { Probability of delayed flight for } \\
\text { Hub-to-Destination }\end{array}$ & Magnitude of flight delays \\
\hline & Cancelled flight & $\begin{array}{l}\text { Probability of cancelled flight } \\
\text { for Origin-to-Hub OR Hub-to- } \\
\text { Destination }\end{array}$ & $\begin{array}{l}\text { Rebooking based on load factor } \\
\text { and frequency of service }\end{array}$ \\
\hline & Inbound delayed flight & $\begin{array}{l}\text { Probability of delayed flight for } \\
\text { Origin-to-Hub such that the } \\
\text { passengers are unable to make } \\
\text { the connection from Hub to } \\
\text { Destination }\end{array}$ & $\begin{array}{l}\text { Rebooking based on load factor } \\
\text { and frequency of service }\end{array}$ \\
\hline
\end{tabular}

For passengers on direct itineraries, the likelihood of a disruption in the form of a cancelled itinerary is a function of the likelihood of a cancelled flight. The magnitude of the delay for this itinerary is determined by the availability of seats on subsequent flights and the frequency of service.

For passengers on connecting itineraries, the likelihood of a disruption in the form of a delayed itinerary is a function of the likelihood of a delayed flight on the hub-to-destination leg. The magnitude of the delay for this itinerary is also determined by the magnitude of the delay of the flight. 
For passengers on connecting itineraries, the likelihood of a disruption in the form of a cancelled itinerary is a function of the likelihood of a cancelled flight on both the origin-tohub or the hub-to-destination legs. The magnitude of the delay for this itinerary is determined by the availability of seats on subsequent flights and the frequency of service.

For passengers on connecting itineraries, the likelihood of a disruption in the form of a missed connection itinerary is a function of the likelihood of a delay on the origin-to-hub flight in excess of the connection window. The magnitude of the delay for this itinerary is determined by the availability of seats on subsequent flights and the frequency of service.

\section{Passenger trip delay metrics}

Reliability in passenger transportation is measured by the difference between ticketed scheduled arrival time and the actual arrival time. This measure takes into account delays accrued by passengers due to delayed and diverted flights, as well as rebooking due to cancelled flights and missed connections.

There are three main metrics used to capture passenger trip reliability (Bratu \& Barnhart, 2005; Sherry \& Wang 2007; Sherry et. al, 2010; Sherry, 2011): (1) Percentage of Passengers Disrupted; (2) Average Trip Delay for Disrupted Passengers; and (3) Total Passenger Trip Delays.

The Percentage of Passengers Disrupted represents the likelihood of a disruption due to delayed flights, cancelled flights, diverted flights or missed connections. The Average Trip Delay for Disrupted Passengers provides a measure of the magnitude of the delays experienced by disrupted passengers, or alternatively, a measure of the expected trip delay experienced by a passenger selected at random from the pool of all passengers. Together, these two metrics define the reliability of the airlines in providing the transportation service from a passenger standpoint.

Annual Total Passenger Trip Delays represents the cumulative delays experienced by passengers. These delays include disruptions due to delayed flights, cancelled flights, diverted flights and missed connections. This is a holistic metric of the magnitude of the trip delay 
phenomenon and is used to estimate lost economic productivity. Total Passenger Trip Delays can be reported on an annual, monthly or daily basis.

\section{Parameters, identities and relationships}

There are three categories of parameters that are used in this model: (i) probability of disruption to itineraries, (ii) magnitude of delays, and (iii) proportion of passengers disrupted. The definitions, identities, and relationships between parameters are defined in this section.

\subsection{Probability of Disrupted Itineraries}

Itineraries can be disrupted by delayed flights, cancelled flights, and missed connections. The probability of an itinerary of type $i$, being disrupted by disruption $\mathrm{j}$ is represented by $\mathrm{p}_{\mathrm{i}, \mathrm{j}}$ where i $\epsilon\{$ direct, connecting $\}$ and $\mathrm{j} \epsilon$ \{delayed, cancelled, miss connected $\}$.

$$
\mathrm{p}_{\mathrm{ij}}=\text { probability of disruption type } \mathrm{j} \text { on itinerary type } \mathrm{i}
$$

where:

$$
\begin{aligned}
& \mathrm{i}=\text { itinerary type, } \mathrm{i} \epsilon \text { \{direct, connecting) } \\
& \mathrm{j}=\text { disruption type, } \mathrm{j} \epsilon \text { (delayed, cancelled, miss connected) }
\end{aligned}
$$

The values of $\mathrm{p}_{\mathrm{ij}}$ are defined by the rules in Table I. These relationships are all based on the probability of a delayed flight which is the complement of flight on-time performance.

$$
\mathrm{p}_{\mathrm{f}}=\text { probability of a delayed flight }=(1-\% \text { flights on-time })
$$

The probability of a disruption of a direct itinerary due to a delayed flight is determined by the likelihood of a delayed flight. Likewise, a connecting itinerary can only be disrupted by a delay on the Hub-Destination segment. The likelihood of this disruption is equivalent to the likelihood of a disruption due to delay of a direct itinerary.

$$
\mathrm{p}_{\text {Connecting, Delayed }}=\mathrm{p}_{\text {Direct, } \text { Delayed }}=\mathrm{p}_{\mathrm{f}}
$$

The probability of a disruption of a direct itinerary due to a cancelled flight is determined by the likelihood of a cancelled fight. The probability of a disruption to a connecting itinerary is twice the likelihood of disruption due to a cancelled flight. A connecting itinerary can be 
disrupted by either the cancellation of the Origin-Hub flight or the Hub-Destination segment. This identity is summarized in Equation 4.

$\mathrm{p}_{\text {Connecting, } \text { Cancelled }}=2 \mathrm{p}$ Direct, Cancelled $=2 \mathrm{p}_{\mathrm{c}}$

where:

$$
\mathrm{p}_{\mathrm{c}}-\text { the probability of a cancelled flight }
$$

There are two underlying causes of cancelled flights: (i) residual cancelled flights due to aircraft equipment failures, (ii) "tactical" cancellations made by the airline to manage emerging delayed flight situations. The latter type of cancellation is a "pressure release valve" used by the airlines when the cumulative schedule for flights arriving at an airport or airspace sector is in excess of the available capacity. Rather than take an excessive flight and crew delay, an airline might choose to rebook the passengers and shuffle aircraft and crew assignments to maintain the integrity of the airline network. In this way cancelled flights are related to flight on-time performance. Analysis of historic monthly data from 2005 to 2010 (BTS, 2011) shows that the probability of a cancelled flight is correlated $\left(\mathrm{R}^{2}=0.64\right)$ with the probability of a delayed flight.

$$
\mathrm{p}_{\mathrm{c}}=0.07 * \mathrm{p}_{\mathrm{f}}
$$

The likelihood of a missed connection is the probability that the flight on the Origin-Hub segment is delayed, multiplied by the probability that the connection at the Hub is missed given that the inbound flight is delayed. A simplified version of this conditional probability, developed by Tien, Subramanian, \& Ball (2008), is shown in Equation 6 with a linear function of tail of the distribution of flight delays as a function of Time-to-Next-Flight.

$$
\begin{aligned}
& \mathrm{p}_{\text {connecting, miss connected }}=[(-0.00083 \mathrm{TNF})+0.2] \mathrm{p}_{\mathrm{f}} \\
& \text { where: }
\end{aligned}
$$

TNF - the average Time-to-Next-Flight.

Table II shows the range of values of the Time-to-Next-Flight term in equation (6) and the range of values of $\mathrm{p}_{\text {connecting, miss connected }}$ for the historic range of probability of a delayed flight (0.2 to 0.3 ) and the average time-to-next flight (120 to 180 minutes). Using this data, without loss of fidelity, the equation for the probability of a missed connection can be simplified to

$$
\mathrm{P}_{\text {connecting, miss connected }}=0.0755 \mathrm{p}_{\mathrm{f}}
$$


Table 2 - Range of values for $p_{\text {connecting, miss connected }}$ for historic range of probability of a delayed flight and time-to-next-flight

\begin{tabular}{cccc}
\hline & tnf & $(\mathbf{- 0 . 0 0 0 8 3 ) ~ t n f ~})+\mathbf{0 . 2}$ & $\mathbf{P}_{\text {connecting, miss connected }}$ \\
\hline & & & \\
\hline .2 & 120 & 0.10 & 0.02 \\
0.2 & 180 & 0.05 & 0.01 \\
0.3 & 120 & 0.10 & 0.03 \\
0.3 & 180 & 0.05 & 0.02 \\
\hline
\end{tabular}

\subsection{Magnitude of Delay for Disrupted Itineraries}

The magnitide of delay experienced by passenegrs due to disrupted itineraries is described in this section. The magnitide of trip delay is defined in units of minutes.

The magnitude of the delay for direct itineraries and connecting itineraries disrupted by a delayed flight is equivalent to the delay for a delayed flight. The magnitude of delay for a delayed flight has historically exhibited an exponential relationship with the probability of a delayed flight. These relationships are defined in the equations below.

$\mathrm{d}_{\text {Direct, Delayed }}=\mathrm{d}_{\text {Connecting, Delayed }}=\mathrm{d}_{\mathrm{f}}$

where:

$\mathrm{d}_{\mathrm{i}, \mathrm{j}}=$ average magnitude of passenger trip delay due to disruption type $\mathrm{j}$ on itinerary type $\mathrm{i}$

$\mathrm{i}=$ itinerary type, $\mathrm{i} \epsilon$ \{direct, connecting)

$\mathrm{j}=$ disruption type, $\mathrm{j} \epsilon$ \{delayed, cancelled, miss connected)

$d_{\mathrm{f}}=$ average passenger trip delay due to a delayed flight

Analysis of monthly historic data from 2007 to 2010 identified a relationship between the average flight delay and the probability of a delayed flight.

$$
\mathrm{d}_{\mathrm{f}}=10.477 \mathrm{p}_{\mathrm{f}}+4.8349
$$


The magnitude of delays for cancelled flights for direct and connecting itineraries, and for missed connections for connecting itineraries, is completely independent of on-time flight performance. Instead these trip delays are a function of the availability of seats for rebooking passengers and the frequency of service.

$$
\mathrm{d}_{\text {direct, cancelled }}=\mathrm{d}_{\text {connecting, cancelled }}=\mathrm{d}_{\text {connecting, miss connected }}=\mathrm{d}_{\text {rebooking }}
$$

where:

$d_{\text {rebooking }}$ - average magnitude of trip delay when rebooked due to a cancelled flight or missed connection

The availability of seats is a function of the average Load Factor. The magnitude of the average delay for rebooked passengers is a function of the Time-to-Next-Flight. Assuming a homogeneous fleet of aircraft, the number of flights to accommodate the passengers on a cancelled flight is Load Factor/(1-Load Factor). For example, the cancellation of a 100 seat flight with a load factor of 0.5 , would take 1 additional 100 seat flights with load factor of 0.5 to rebook all the passengers. Rebooking the same flight with a load factor of 0.9 would take 10 flights. The relationship between Load Factor and number of flights to rebook is shown in Figure 2 along with exponential model fit to the data.

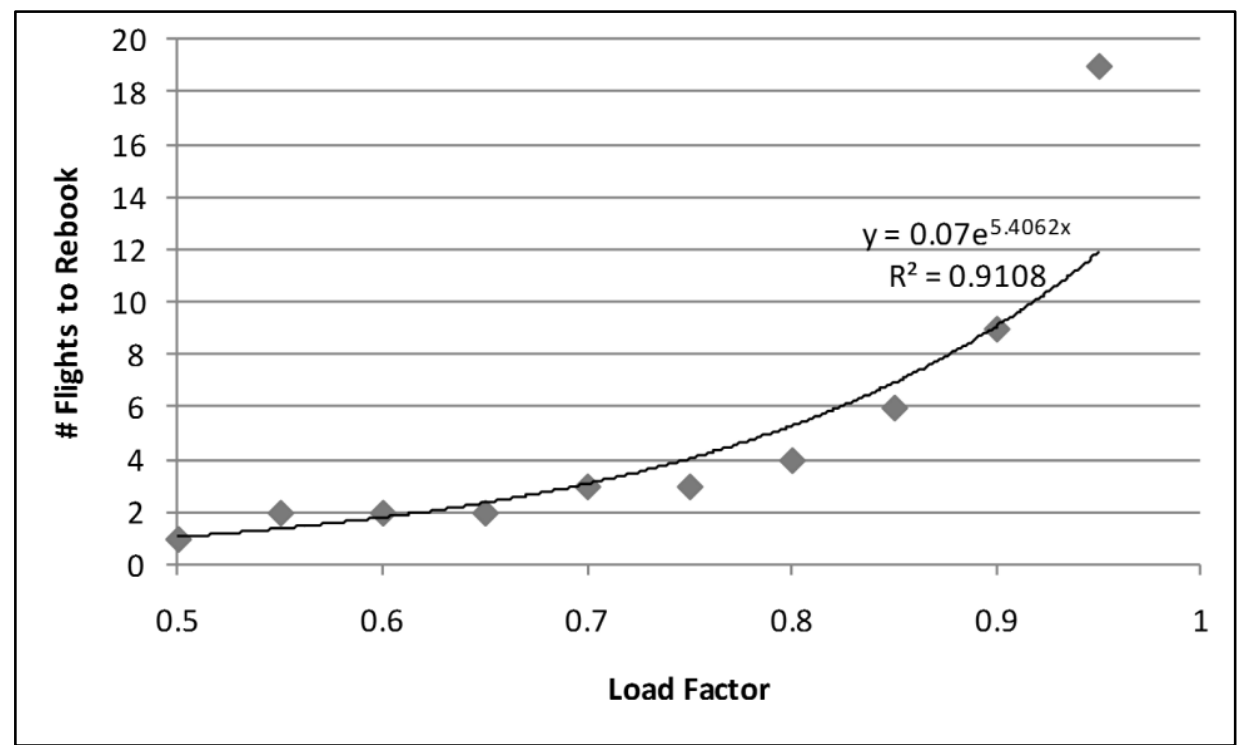

Figure 2 - Relationship between Load Factor and the number of flights required to accommodate rebook passengers based on the "physics" of re-booking 
Based on this model, the average trip delays for passengers on rebooked flights can be approximated as follows:

$$
\mathrm{d}_{\text {rebooking }}=(0.5)\left(0.07 \mathrm{e}^{(5.4062 * \mathrm{lf})}\right)(\operatorname{tnf})
$$

where:

$$
\begin{aligned}
& \text { If - Load Factor is the percentage seats occupied } \\
& \text { tnf - Time-to-Next-Flight is the average time to the next flight }
\end{aligned}
$$

\subsection{Passengers on each Type of Itinerary}

The number of passengers on direct itineraries and connecting itineraries can be defined as a function of the fraction of passengers on direct itineraries and the Total Passengers.

Passengers on Direct Itineraries $=\mathrm{f}_{\mathrm{d}} \mathrm{T}$

Passengers on Connecting Itineraries $=\mathrm{f}_{\mathrm{c}} \mathrm{T}$

where:

$$
\begin{aligned}
& \mathrm{f}_{\mathrm{d}}=\text { fraction of passengers on direct itineraries } \\
& \mathrm{f}_{\mathrm{c}}=\text { fraction of passengers on connecting itineraries } \\
& \mathrm{T}=\text { total passenger trips }
\end{aligned}
$$

By definition, the fraction of passengers on connecting itineraries is the complement of the faction of passengers on direct itineraries defined by the identity in equation 14 .

$$
f_{d}=\left(1-f_{c}\right)
$$

Data for Enplanements is more readily available than data on count of passenger trips. Equation 15 provides a simple relationship to convert Enplanements to Total Passenger Trips. Enplanements is a count of the passengers that board each individual flight. As a result, passengers on connecting itineraries are counted twice in the data for Enplanements. Note: passenger trips with 2 or more connections have historically represented less than $2.3 \%$ of the passenger trips and are not taken into consideration in this analysis. The relationship between 
enplanements, total passenger trips, and fraction of passengers on each itinerary type is defined in Equation 15.

$$
\begin{aligned}
& \text { Enplanements }=\mathrm{T}\left(2-\mathrm{f}_{\mathrm{d}}\right) \\
& \mathrm{T}=\text { Enplanements } /\left(2-\mathrm{f}_{\mathrm{d}}\right)
\end{aligned}
$$

\section{Derivation of passenger trip reliability metrics}

This section provides the derivation of the non-dimensional passenger trip delay metrics: (1) Percentage of Passengers Disrupted; (2) Average Trip Delay for Disrupted Passengers; and (3) Total Passenger Trip Delays.

\subsection{Percentage of Passengers Disrupted}

The Percentage of Passengers Disrupted represents the likelihood of a disruption due to delayed flights, cancelled flights, diverted flights or missed connections. A probabilistic model of the Percentage of Passengers Disrupted, described in the Equation (1), captures the likelihood of trip disruptions by delayed, cancelled, and missed connected itineraries. Each category of disruption is dependent on the type of itinerary and is weighted by the fraction of passengers on each type of itinerary. The likelihood of being disrupted on a direct itinerary is a function of the likelihood of being on a delayed flight or a cancelled flight. The likelihood of being disrupted on a connecting itinerary is a function of the likelihood of being on a delayed flight, a cancelled flight, or a missed connection.

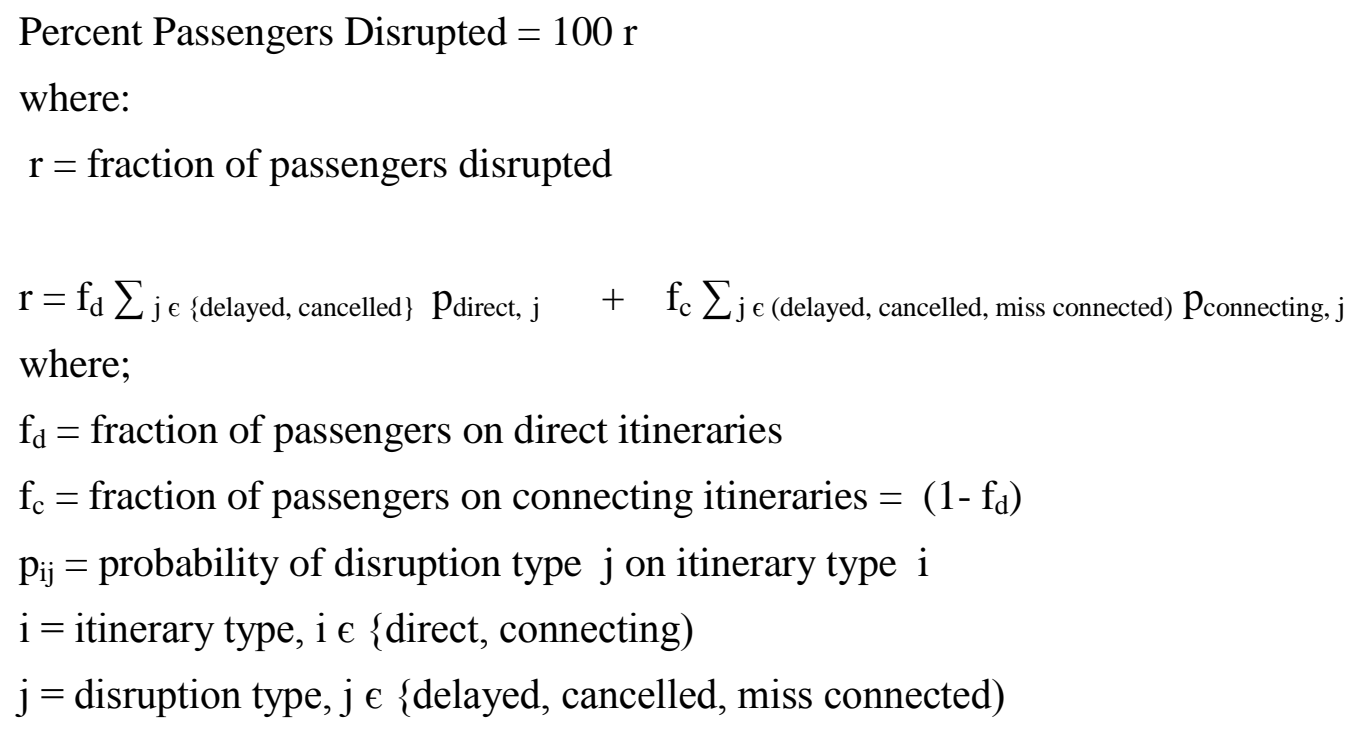


Substituting the identities and relationships described in Section 4 the Equation (17) can be reformulated.

$$
\begin{aligned}
& r=f_{d}[p f+0.07 p f]+\left(1-f_{d}\right)\left[p f+2(0.07 p f)+0.0755 p_{f}\right] \\
& \text { Percentage of Passengers Disrupted }=r=1.24 p_{f}-f_{d}\left[0.15 p_{f}\right]
\end{aligned}
$$

\subsection{Average Trip Delay for Disrupted Passengers}

The Average Trip Delay for Disrupted Passengers provides a measure of the magnitude of the delays experienced by disrupted passengers (see Equation 4). The Average Trip Delay for Disrupted Passengers is expected delays, probability of each disruptions multiplied by the magnitude of the delay for each disruption, weighted by the number of passengers on each type of itinerary.

Average Trip Delay for Disrupted Passengers $=$

$$
\begin{aligned}
& \mathrm{f}_{\mathrm{d}}\left[\left(\mathrm{p}_{\text {direct, delayed }} * \mathrm{~d}_{\text {direct, delayed }}\right)+\left(\mathrm{p}_{\text {direct, cancelled }} * \mathrm{~d}_{\text {direct, cancelled }}\right)\right]+ \\
& \mathrm{f}_{\mathrm{c}}\left[\left(\mathrm{p}_{\text {connecting, delayed }} * \mathrm{~d}_{\text {connecting, delayed }}\right)+\left(\mathrm{p}_{\text {connecting, cancelled }} * \mathrm{~d}_{\text {connecting, cancelled }}\right)+\left(\mathrm{p}_{\text {connecting, }}\right.\right.
\end{aligned}
$$

The first term in Equation 19 accounts for the passengers on direct itineraries disrupted by delayed flights and cancelled flights. The second term accounts for passengers on connecting itineraries disrupted by delayed flights, cancelled flights and missed connections. The contribution of these terms is determined by the relative values of $p_{i, j}$ and $d_{i, j}$. By substituting the identities defined above, equation for Average Trip Delay for Disrupted Passengers can be simplified to:

Average Trip Delay for Disrupted Passengers $=$

$$
\mathrm{f}_{\mathrm{d}} \mathrm{p}_{\mathrm{f}}\left[-0.1455 \mathrm{~d}_{\text {rebooking }}\right]+\mathrm{p}_{\mathrm{f}}\left[\left(300 \mathrm{p}_{\mathrm{f}}-21\right)+0.2155 \mathrm{~d}_{\text {rebooking }}\right]
$$

\subsection{Total Passenger Trip Delay}

The Total Passenger Trip Delay is the sum of the trip delays experienced by each passenger.

$$
\begin{aligned}
& \text { Total Passenger Trip Delay }= \\
& T\left(f_{d} p_{f}\left[-0.1455 d_{\text {rebooking }}\right]+p_{f}\left[\left(300 p_{f}-21\right)+0.2155 d_{\text {rebooking }}\right]\right)
\end{aligned}
$$




\section{Conclusion}

A model for converting flight delay data into passenger trip delay metrics is derived. The model accounts for passenger trip delays due to cancelled flight and missed connections, in addition to flight delays. The model also accounts for the structure of the network such as the ratio between direct and connecting itineraries, the time between banks at the hubs, the frequency of service, and the selection of aircraft size and target load factors. The model is explicitly designed to account for the network structure.

\section{Limitations of Model}

This model is an aggregate model of the average behavior of the airline transportation system. As a consequence, the model is limited in it's ability to estimate the response to specific events (e.g. snowstorm in New York region), but representative of the overall performance of the system over an extended period of time. For example, a comparison of the Average Trip Delay for Disrupted Passengers from this model with the estimated Average Trip Delay for Disrupted Passengers from Sherry (2010) for each day in June 2007 yielded a mean error of 1.86 minutes with a standard deviation of 20.7 minutes.

In this way, this model is best used as an "index" in assessing changes from one period to the next, the changes resulting from network structure changes, or the impact of new concepts of operations/technologies.

The limitations of the model are the result of simplifying assumptions in representing the physics of the process (e.g. rebooking delays) and from the simplified gross behavior of the airline transportation system (e.g. flight cancellations, missed connection likelihood). The rebooking delays are derived from a model of re-accommodating passengers based on Load Factors and Time-to-Next Flight. This simplified rebooking model is based on average Load Factors and average Time-To-Next-Flight, on the assumption that the distributions are symmetrical and that the average will err on the high side as much as the low. For the case of Load Factor this is a valid assumption. Time-to-Next-Flight, however is an asymmetric distribution with a long right-tail. 
The probabilities of cancelled flights and missed connections, and the magnitude of delays for delayed flights are derived from aggregate historic data. By definition, these relationships reflect the average behavior of the system in response to delayed flights over an extended period of time. Variations in performance, such as differences in passenger trip delays due to curtailed capacity in the southeast (e.g. convective weather impacting DFW, ATL, IAH) versus curtailed operations in the mid-west (e.g. snowstorm impacting ORD, MSP, DTW) are not captured in the model. Further, the cancellation and missed connection elements of the model are derived from historic data. Should airlines significantly change the response to flight and/or passenger disruptions (e.g. collaborative decision making, use of spare aircraft), these relationships would need to be updated.

\section{Understanding Passenger Trip Delay Reliability Metrics}

The model for the Passenger Trip Reliability Metrics provides insights into the role of flight delays and network structure on passenger trip delays. The Percentage of Passengers Disrupted is determined primarily by the probability of delayed flights. The coefficients reflect the relationship between the likelihood of a delayed flight, and the likelihood of a cancelled flight or a missed connection. The low likelihood of cancelled flights $(\sim 2 \%)$ and missed connections $(\sim 3 \%)$ adjust the baseline probability of a delayed flight.

The fraction of passengers on direct and connecting itineraries has plays only a small role in determining the Percentage of Passengers Disrupted. Increasing the number of passengers on direct flights has the effect of decreasing the percentage of passengers disrupted.

The Average Trip Delay for Disrupted Passengers and Total Passenger Trip Delays are directly a function of the probability of delayed flights and rebooking delays. The Average Trip Delay increases to the square of the probability of a delayed flight and linearly with relationship to rebooking delays.

\section{Benefits Analysis for Modernization}

This paper has shown that passenger trip reliability is determined by flight performance factors (i.e. flight on-time performance) as well as factors that have nothing to do with flight performance (i.e. load factors, frequency of service, and itinerary design). As shown by this 
analysis, the estimates of the benefits accrued by the reduction of passenger trip delays are under-estimated for NAS simulations that do not explicitly account for the delay experienced by passengers on cancelled or miss connected itineraries.

In addition, a complete accounting requires the analysis of passenger itineraries. Statement of benefits should include a set of assumptions associated with the structure of the network. Airline mergers and acquisitions that change the structure of the itinerary network, airlines fleet mix decisions, airline hub-and-spoke designs and frequency of service decisions, and airline revenue management decisions with regard to target load factors, impact total passenger trip delays.

\section{Consumer Protection and Rebooking Performance}

The model described in this paper highlights the role enterprise decision, such as competitive strategies and cost structures, can have on passenger trip reliability. In addition to the inherent complexity, the factors that affect passenger trip reliability cross traditional boundaries of jurisdiction and prevent any one enterprise (e.g. government or a single airline) from addressing issues associated with passenger trip metrics. Airline decisions affecting load factors, aircraft size, itinerary service, and bank structure are at the core of the competitive strategies of the airlines that, in theory, leads to price competition and benefits to consumers. As a consequence, they have historically been outside the jurisdiction of government oversight and regulation. Any government attempt to legislate across these boundaries is likely to impact the competitive structure of the airline business.

In light of these issues, Passenger Bill of Rights legislation, that set service standards for airline passengers, must address both the flight on-time performance as well as the rebooking performance. Failure to account for re-booking performance addresses only one component of the overall phenomenon. 


\section{Acknowledgment}

The author acknowledges the technical contributions to the paper of Dr. John Shortle, Ashwin Samant, John Ferguson, Vivek Kumar, Dr. George Donohue, Akshay Belle (Center for Air Transportation Systems Research at George Mason University), Natalia Alexandrov, Michael Madson, Rosa Oseguera-Lohr (NASA), Peggy Gervasi, Yuri Gawdiak (JPDO), Shahab Hassan, Dou Long, Anthony DeCicco (LMI), Terry Thompson, Bengi Manley, Danyi Wang, Norm Fujisaki, Giles O'Keefe (Metron Aviaton), .Joe Post, Dan Murphy, Kimberly Noonan, Tony Diana, Akira Konde (FAA), Ed Lassiter (SWA), Jianfeng Wang (United Airlines), Loan Le (American Airlines). This project was funded by internal funding from Center for Air Transportation Systems Research at George Mason University.

\section{References}

Baik, H., Li, T., Chintapudi, N. (2010) Estimation of Flight Delay Costs for U.S. Domestic Air Passengers. Transportation Research Record. Journal of the Transportation Research Board, $\mathrm{n}$. 2177, p. 49.

Ball, M., Lovell, D., Mukherjee, A. and Subramanian, A. (2006) Analisys of Passenger Delays: Developing a Passenger Delay Metric. NEXTOR NAS Performance Metrics Conference, ASilomar, CA. March

Barnhart, C., Fearing, D. and Vaze, V. (2010) Modeling Passenger Travel and Delays in the National Air Transportation System. Working paper.

Bilimoria, K. D., Sridhar, B., Chatterji, G. B., Sheth, K. S. and Grabbe, S. R. (2001) FACET: Future ATM Concepts Evalutaion Tool. Air Traffic Control Quarterly, vol. 9, n. 1, pp. 1-20.

Bratu, S. and Barnhart, C. (2005) An Analysis of Passenger Delays Using Flight Operations and Passenger Booking Data. Journal of Transportation and Statistics, n. 1, vol. 13, pp. 1-27.

Bureau of Transportation and Statistics (2011) Airline On-Time Performance Data, Form 41 Traffic T100 Domestic Segment Data, DB1_B Coupon Data. Available at www.transtats.bts.gov. 2010

Department of Transportation (2003) Revised Departmental Guidance: Valuation of Travel Time in Economic Analysis. Office of the Assistant Secretary for Transportation Policy. Memorandum. Available at /ostpxweb.dot.gov/policy

Federal Aviation Administration (2010) Airport Improvement Program. Website for FAA Airports business unit. www.faa.gov/airports/aip/

JPDO (2010) FAA's NextGen 2010 Implementation Plan. Available at www.faa.gov/nextgen

Long, D., Wingrove, E., Lee, D., Gribko, J., Hemm, R., and Kostiuk, P. (1999) A method for evaluating air carrier operational strategies and forecasting air traffic with flight delay. National Aeronautics and Space Administration (NASA). NASA Contract No. NAS2-14361. NS902S1. Logistics Management Institute (LMI). McLean, Virginia.

Millner, D. C. (1993) Design of the NASPAC simulation modeling system. Technical Report MTR 92W0000135, The MITRE Corporation, McLean, VA. FAA. Contract No. DTFEA01-93-C00001.

NEXTOR (2010) Total Delay Impact Study: A Comprehensive Assessment of the Costs and Impacts of Flight Delay in the United States. Report prepared for FAA Air Traffic organization Strategy and Performance Business Unit Washington D.C. Available at www.isr.umd.edu. 
Post, J. (2011) NextGen Modeling Requirements: The AXTO Perspective. 5th Integrated Communications Navigation and Surveillance Conference, Dulles, Virginia. May 10-12, 2011

Ramamoorthy, K., Boisvert, B., and Hunter, G. (2006) A Real-Time Probabilistic Traffic Flow Management Evaluation Tool. 25th Digital Avionics Systems. IEEE/AIAA Conference, pp. 1-13.

Sherry, L. and Wang, D. (2007) Air Travel Consumer Protection: Metric for Passenger On-Time Performance. Transportation Research Record, pages 22-27.

Sherry, L., Samant, A., Calderon-Meza, G. (2010) Trends in Airline Passenger Trip Delays (2007): A Multi-Segment Itinerary Analysis. American Institute of Aeronautics and Astronautics: 10th AIAA Aviation Technology, Integration, and Operations (ATIO) Conference, Sept.

Sherry, L. (2011) Modeling Passenger Trip Reliability: Why NextGen May Not Improve Passenger Delays. The Journal of Air Traffic Control, vol. 53, n. 3.

Subramanian, B. (2007) Aggregate Statistical Models for National Airspace System Performance. MS thesis, University of Maryland, College Park.

Sweet, D. N., Manikonda, V., Aronson, J. S., Roth, K., and Blake, M. (2002) Fast-time simulation system for analysis of advanced air transportation concept. AIAA Modeling and Simulation Conference.

Tien, S. A., Subramanian, B. and Ball, M. (2008) Constructing a Passenger Trip Delay Metric: An Aggregate-level Approach. Proceedings International Conference on Research in Air Transportation (ICRAT-2008), Fairfax, VA, 2008.

Wang, D. (2007) Methods For Analysis Of Passenger Trip Performance In A Complex Networked Transportation System. Dissertation, Systems Engineering and Operations Research Department, George Mason University.

Zhu, Y. (2007) Evaluating Airline Delays: The Role of Airline Networks, Schedules and Passenger Demands. Master's Thesis, MIT, Cambridge, Massachusetts. 